\title{
Particle stability and structure on the peritoneal surface in pressurized intra-peritoneal aerosol chemotherapy (PIPAC) analysed by electron microscopy: First evidence of a new physical concept for PIPAC
}

\author{
TANJA KHOSRAWIPOUR ${ }^{1,2}$, JUSTYNA SCHUBERT $^{3}$, VERIA KHOSRAWIPOUR ${ }^{4}$, HARIS CHAUDHRY $^{1}$, \\ JAKUB GRZESIAK $^{5}$, MOHAMED ARAFKAS $^{6}$ and AGATA MIKOLAJCZYK ${ }^{7}$
}

\begin{abstract}
${ }^{1}$ Division of Colorectal Surgery, Department of General Surgery, University of California, Irvine, Orange, CA 92868, USA; ${ }^{2}$ Department of Surgery (A), University Hospital Duesseldorf, Duesseldorf D-40225, Germany; ${ }^{3}$ Department of Food Hygiene and Consumer Health Protection, Wroclaw University of Environmental and Life Sciences, 50-375 Wroclaw, Poland; ${ }^{4}$ Department of Orthopedic and Trauma Surgery, Ortho-Klinik Dortmund, Dortmund D-44263, Germany; ${ }^{5}$ Electron Microscopy Laboratory, Wroclaw Research Centre EIT+, 54-066 Wroclaw, Poland; ${ }^{6}$ Department of Plastic Surgery, Ortho-Klinik Dortmund, Dortmund D-44263, Germany; ${ }^{7}$ Department of Biochemistry and Molecular Biology, Faculty of Veterinary Sciences, Wroclaw University of Environmental and Life Sciences, 50-375 Wroclaw, Poland
\end{abstract}

Received October 19, 2018; Accepted January 17, 2019

DOI: $10.3892 / \mathrm{ol} .2019 .10162$

\begin{abstract}
Pressurized intra-peritoneal aerosol chemotherapy (PIPAC) has been introduced to the clinical setting as a novel approach for the treatment of peritoneal metastasis. The local interaction of chemoaerosol droplets with the peritoneal surface as well as their distribution pattern is considered the main advantage over conventional liquid intraperitoneal chemotherapy. The aim of the present study was to investigate the behavior of these aerosol particles during PIPAC application via electron microscopy. Solutions of doxycycline, liposomal doxorubicin and macrophage cells were aerosolized using an established ex-vivo model. PIPAC was performed on peritoneum samples via microcatheter (MC) at a pressure of $12 \mathrm{mmHg} \mathrm{CO}_{2}$ at $27^{\circ} \mathrm{C}$. Following PIPAC the surface structure of applied particles was measured via electron microscopy.The aerosol particle contact of doxycyclin created a nanofilm of $\sim 200 \mathrm{~nm}$ height on the peritoneal surface, and this height was revealed to be independent of the size of the initial particle hitting. These nanofilm blocks of 'cylinders' are of different diameters depending on the initial aerosol particle hitting that spot. Diameters of these 'cylinders' are far wider than the original diameter of the
\end{abstract}

Correspondence to: $\mathrm{Dr}$ Tanja Khosrawipour, Division of Colorectal Surgery, Department of General Surgery, University of California, 333 City Boulevard West, Suite 850, Irvine, Orange, Orange County, CA 92868, USA

E-mail: tkhosrawipour@gmail.com

Key words: ex-vivo, electron microscopy, Pressurized Intra-Peritoneal Aerosol Chemotherapy, peritoneal metastasis, nanoparticles initial aerosol particle. However, coated particles such as liposomal doxorubicin and macrophages remained intact following contact with the peritoneal surface. Based on this and other data, the concept that aerosol particles exhibit a gas-like behavior in the abdomen creating a therapeutic capnoperitoneum should be revised. Fluid aerosol particles collide with the peritoneum creating a nanofilm. The interaction of pressurized intraperitoneal aerosol on the peritoneum is therefore closer to the distribution of a liquid film than to that of a gas. Further studies are required to further analyze the interaction of this nanofilm on the peritoneum.

\section{Introduction}

Since the survival benefit of intraperitoneal chemotherapy (IPC) in peritoneal metastasis (PM) has been shown a decade ago, this field has been under intense study with new developments in treatment and drug application. While IPC is an important therapeutic option, it has significant shortcomings such as high local complication rates with regards to its application devices, heterogeneous intraperitoneal drug distribution and limited tissue penetration rates. Pressurized intra-peritoneal aerosol chemotherapy (PIPAC) has been introduced as a new treatment option with the potential to overcome these technical and biological limitations. Using an aerosol creating device, the drug containing solution is delivered into the abdominal cavity in a $12 \mathrm{mmHg}$ 'therapeutic capnoperitoneum' in the shape of micro droplets. In-vivo animal experiments report 'gas-like' (1) behavior of the aerosol droplets. An extensive amount of clinical studies regarding PIPAC's efficacy as a treatment option in peritoneal metastasis has been performed $(2,3)$. Moreover, previous studies have established a basic understanding of technical $(4,5)$, biological $(6,7)$ and applicational (8) principles. However, the 
actual collision of aerosol particles applied via PIPAC onto the peritoneal surface has not been adequately studied. Up to this day it mostly remains unclear how the particles interact with the peritoneal surface. While there are speculations on the interaction of these particles with the peritoneal surface, most studies have concentrated to measure clinical effects (2) and tissue concentrations or penetration rates $(9,10)$ without any regard for the particle-surface interaction on an electron microscopic level. The aim of the present study is to establish a better understanding for this particle-surface interaction. For this purpose, we performed PIPAC with fluid solutions and different particles to investigate their morphology and physical appearance on the peritoneal surface.

\section{Materials and methods}

Ex-vivo PIPAC model. The experiments were performed using a standard ex-vivo model with (A) doxycycline solution, (B) liposomal doxorubicin and (C) a eukaryotic cell line (macrophages). PIPAC was performed on peritoneal tissue samples from swine which are commercially available. Therefore, no approval of the Institutional Review Board and no consent of the Local Board on Animal Care were required. The ex-vivo PIPAC model is well established and has been previously described in many studies $(8,11)$. A commercially available hermetic plastic box with a total volume of 3.5 liter, mimicking the abdominal cavity, was used. In the center of the top cover of the plastic box, a $5 \mathrm{~mm}$ trocar (Kii ${ }^{\circledR}$ Balloon Blunt Tip System, Applied Medical, Rancho Santa Margarita, CA, USA) was placed. The nozzle of the MC was introduced into the trocar and the insufflator was connected. The plastic box was kept at constant room temperature of 27 degrees Celsius during the whole procedure. A peritoneal tissue sample of approximately $2 \mathrm{~cm}^{2}$ from the swine specimen was placed in the rear of the box to the side wall (Fig. 1). The plastic box was then tightly sealed and a constant $\mathrm{CO}_{2}$ capnoperitoneum of $12 \mathrm{mmHg}$ (Olympus UHI-3; Olympus Medical Life Science and Industrial Divisions, Olympus Australia Pty., Ltd., Notting Hill, VIC, Australia) was established for every single procedure. All experiments were repeated and independently performed three times.

Microcatheter. The microcathter (MC; PW-205V Olympus Surgical Technologies Europe, Hamburg, Germany) consists of a connecting device with a pressure line connecting the shaft to the nozzle. The nozzle head has a small central opening. A total of $10 \mathrm{ml}$ of each sample is delivered with a constant flow using a $10 \mathrm{ml}$ syringe and high manual pressure $(1 \mathrm{ml} / \mathrm{sec})$. The MC generates a polydisperse aerosol.

PIPAC of liquid solution. Peritoneal tissue samples were first covered with a bacterial layer. This was done to create a contrast in order to detect aerosol particles as described below. Escherichia coli strain PMC175 (commercially available) frozen stock cultures were resuscitated by plating on LB agar, poured into Petri dishes and incubated at $37^{\circ} \mathrm{C}$ overnight. Single colonies from agar plates were transferred to $4 \mathrm{ml}$ of $\mathrm{LB}$ broth in test tubes. After $3 \mathrm{~h}$ of culturing $\left(37^{\circ} \mathrm{C}, 180 \mathrm{rpm}\right)$, $1 \mathrm{ml}$ of bacteria culture was centrifuged ( $3 \mathrm{~min}, 2,700 \mathrm{x} \mathrm{g}$ ), washed three times in sterile $0.9 \% \mathrm{NaCl}$, resuspended in $1 \mathrm{ml}$ of sterile $0.9 \% \mathrm{NaCl}$ and diluted ten times. A total of $1 \mathrm{ml}$ of such a suspension was poured onto peritoneal tissue samples and incubated at $37^{\circ} \mathrm{C}$ overnight. The next day these samples were put into the ex-vivo box. PIPAC was performed with $10 \mathrm{ml}$ doxycycline solution at a $20 \mathrm{mg} / \mathrm{ml}$ concentration. Tissue samples were removed after PIPAC for electron microscopy.

PIPAC of liposomal doxorubicin solution. A peritoneal tissue sample of approximately $2 \mathrm{~cm}^{2}$ from the swine specimen was placed in the rear of the box to the side wall and PIPAC was performed with $10 \mathrm{ml}$ liposomal doxorubicin $\left(\right.$ Caely ${ }^{\circledR}$, European trademark of Doxil ${ }^{\circledR}$, Janssen-Cilag, BHZ0V00) solution at $0.6 \mathrm{mg} / 10 \mathrm{ml}$ concentration.

PIPAC of macrophages. HD11 cells (HD11 cell line; Roslin Institute, Easter Bush, Midlothian, Scotland, UK) were maintained in RPMI 1640 supplemented with $10 \%$ fetal calf serum (FCS; Invitrogen; Thermo Fisher Scientific, Inc., Waltham, MA, USA), $2 \mathrm{mM}$ L-glutamine, $1 \mathrm{mM}$ sodium pyruvate, $0.1 \mathrm{mM}$ Non-Essential Amino Acids and antibiotics (Penicillin $0.06 \mathrm{mg} / \mathrm{ml}$; Streptomycin $0.1 \mathrm{mg} / \mathrm{ml}$ ). The cells were grown in a humidified $5 \% \mathrm{CO}_{2}$ atmosphere. To evaluate cell population density (i.e., the total number of living cells in the culture) and cell viability (i.e. the percentage of living cells in the sample), Trypan Blue (TB) dye exclusion assay with a haemocytometer grid (Thoma neu chamber) was used. Cells were trypsinized, centrifuged and resuspended in $10 \mathrm{ml}$ of medium. Then, PIPAC was performed on the peritoneal surface with $10 \mathrm{ml}$ medium.

Particle detection on Electron microscopy. The surface of a representative amount of the peritoneal tissue samples A, B and $\mathrm{C}$ was analyzed and visualized via cryogenic scanning electron microscopy (cryo-SEM). Tissues were fixed overnight in a $2.5 \%$ glutaraldehyde solution in phosphate buffer $(\mathrm{pH}=7.2)$. After fixation, samples were washed in phosphate buffer, rinsed in ultrapure (filtered through $0.1 \mu \mathrm{m}$ syringe filter) deionized water, mounted on cryo shuttle using OCT/colloidgraphite mixture and plunged in liquid nitrogen. Frozen specimen were then quickly transferred to cryo-preparation chamber (Cryo Quorum PP3010T) and sputtered with a conductive layer of platinum at $-140 \mathrm{C}^{\circ}$, followed by a transfer to the microscope chamber maintaining the same temperature $-140 \mathrm{C}^{\circ}$ (Auriga60; Zeiss AG, Oberkochen, Germany). Samples were observed at 2 kilo Volt of acceleration voltage using In Lens and SE2 secary electron detectors.

Statistical analyses. All experiments were independently performed three times. The statistical presentation of the doxycyclin part of the experiment was demonstrated separately. This was performed with Sigma Plot 12 (Systat Software Inc., San Jose, CA, USA). The presented data is subject of one representative tissue sample. The distribution of the particle amount for different diameters is listed.

\section{Results}

While the aerosol particles of the doxycyclin solution entirely collapsed on impact with the peritoneal surface, all other particles remained intact following PIPAC and the fixation 


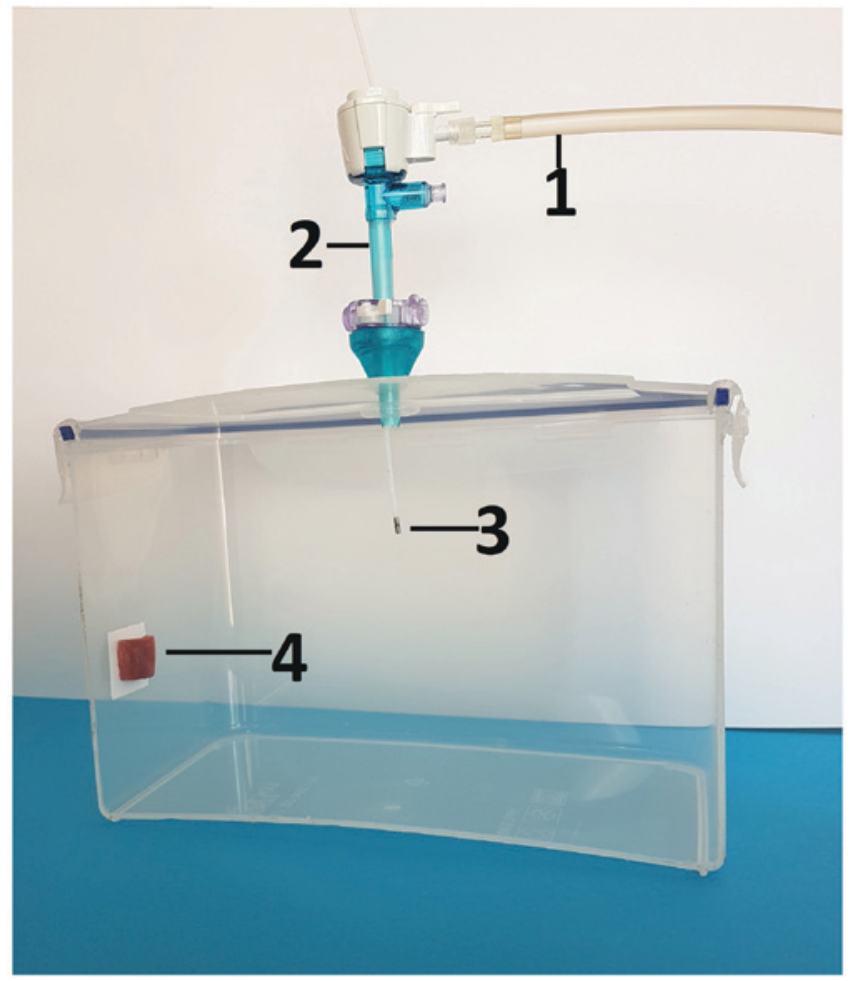

Figure 1. Laparoscopy-assisted ex-vivo experiment on fresh swine peritoneum investigating the submicroscopic particle behavior of aerosolized material in PIPAC via MC device. For better demonstration, the front wall of the plastic box (ex-vivo PIPAC model) has been removed. MC is placed in the center of the top in a $5 \mathrm{~mm}$ trocar. 1) insufflation tube, 2) trocar 3) microcatheter, 4) tissue samples at the rear of the box. MC, microcatheter.

procedure for electron microscopy (Fig. 2A and B). Neither small particles like liposomal doxorubicin nor macrophage cell lines disintegrated (Fig. 2C and D). Doxycyclin aerosol particles created 'cylinder like' blocks on the peritoneal surface. These were in round shapes and, in some cases, merged into connecting round blocks. These 'cylinder like' blocks covered less than $40 \%$ of the peritoneal surface. While the diameter of those cylinders extensively varied at around 50-170 $\mu \mathrm{m}$ (Fig. 2A and B), their height was quite constant at around $200 \mathrm{~nm}$ (Fig. 3). Based on the gathered data with regard to given height and diameter of every cylinder the volume of these cylinders was calculated and presented (Fig. 4) with the following formula:

$$
V_{\text {Zylinder }}=\pi r^{2} h_{\text {hight }}
$$

The calculated volume for the cylinder was then related to the volume of the initial doxycycline aerosol particle hitting the peritoneal surface. It is known that aerosol particles create a sphere-like structure while floating through their gas environment (12). With the volume of that sphere, its initial diameter prior to peritoneal contact was calculated with the following formula:

$$
\mathrm{V}_{\text {Sphere }}=\frac{4}{3} \pi r^{3}
$$

Measured diameters were placed in 3 groups, group 1 diameter $<13 \mu \mathrm{m}$, group 2 diameter 13-17 $\mu \mathrm{m}$ and group 3 diameter $>18 \mu \mathrm{m}$ (Fig. 4). Most particles had a diameter between 13-17.9 $\mu \mathrm{m}$. Accordingly, aerosol particles that were either smaller or larger than described had less contact with the peritoneal surface. Single liposomal doxorubicin particles lied on the peritoneal surface or accumulated to larger configurations. These particles showed a round spherical form. The size of most particles varied around 0.5-2 $\mu \mathrm{m}$ (Fig. 2C). The 3-Dimensional form of these liposomal particles remained stable following PIPAC as well as after contact with the peritoneum and following fixation procedures. Single macrophage cells could be detected on the peritoneal surface. These still seemed to be intact (Fig. 2D).

\section{Discussion}

IPC delivered as a pressurized aerosol in form of PIPAC has been introduced as a new and innovative approach to improve the treatment of advanced, multiresistant PM. Some national and international medical centers have just started PIPAC applications and are using recommended standard protocols, methodology and indications as initially described (13). Current clinical and experimental research focuses on analyzing changes in PIPAC application as well as on introducing PIPAC procedures to a broader clinical context (14). From the beginning, this application has been reported to potentially overcome some of the limitations observed with conventional liquid IPC as used in HIPEC.

Special physical properties of PIPAC technology may significantly change the behavior and effects of applied substances. With regard to more than 70 studies that have been conducted on PIPAC, it still remains mostly unknown how these aerosol particles interact with the peritoneal surface and how they may disintegrate following impaction. To our knowledge this is one of the first studies to demonstrate this particle interaction and to propose a concept beyond the initial model of a 'therapeutic capnoperitoneum'. The model of a therapeutic capnoperitoneum that was initially proposed (1) has partially failed and this model has not been replaced with a new concept, failing to explain some of the results of many experimental studies performed in recent years. Further studies have demonstrated that PIPAC via a monocomponent nozzle consists of a spray effect of accelerated fluid and an additional aerosol particle creation $(15,16)$ without exhibiting all aspects that would be considered gas-like effects . The created aerosol particles are polydisperse and vary in size. It has been suggested that locations outside the area of the main sprayjet can only be reached by smaller particles. However, there was little knowledge on what particles sizes are considered. Larger particles are assumed to directly contact the peritoneum due to gravitational force (15). However, it has been assumed that while some smaller particles may reach the periphery, some particles might be even too small to come into contact with the peritoneum as they are under little gravitational effect. These particles are assumed to be $\leq 5 \mu \mathrm{m}$ in diameter. Due to their small size, they might float in the surrounding $\mathrm{CO}_{2}$ capnoperitoneum without peritoneal surface interaction for a long time. Based on these first important studies, one major consideration was to be able to influence the behavior of still floating aerosol particles and redirect them to the peritoneal surface by means of electrostatic precipitation $(17,18)$. At this point of research, it became clear that the concept of a 'gas 

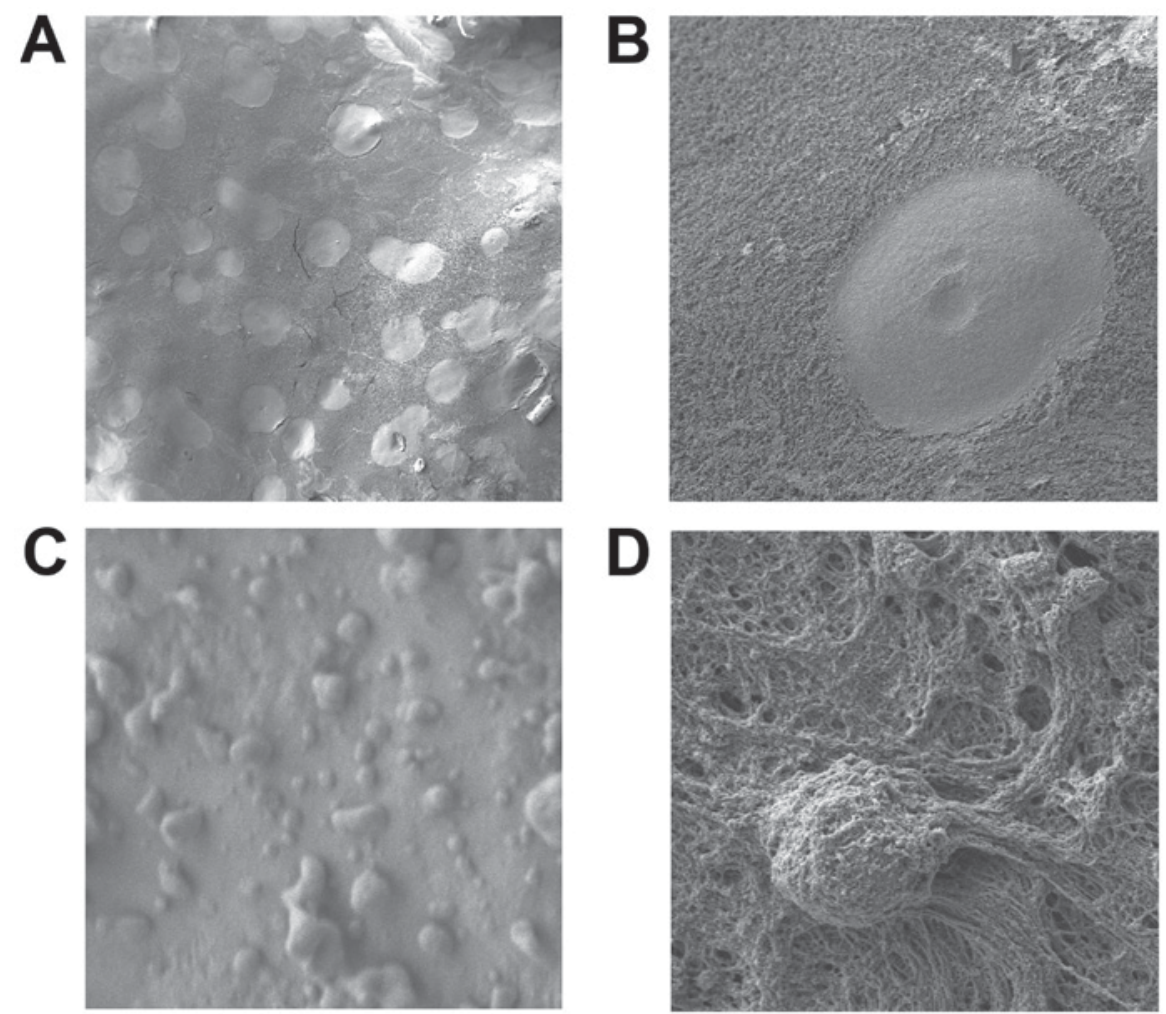

Figure 2. Electron microscopy at different ML of doxycyclin aerosol particles after collision onto the peritoneal surface covered by a thin layer of Escherichia coli, (A) x100 ML and (B) x1,000 ML. (C) Structurally Intact Liposomal doxorubicin particles x14.000 ML and (D) macrophages x10.000 ML) on the peritoneal surface (lower pictures). ML, magnification levels.

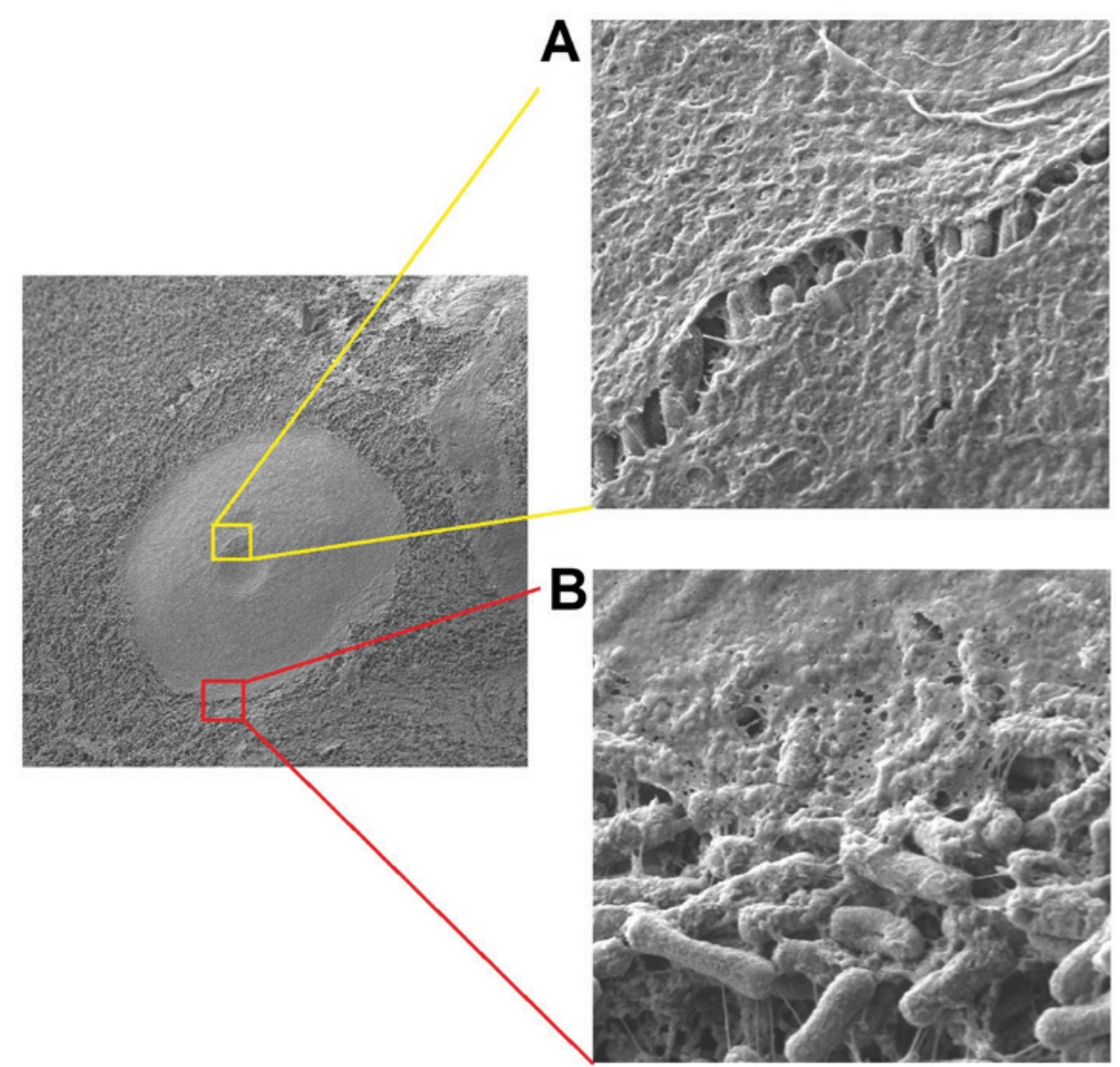

Figure 3. Left picture: Electron microscopy and magnifications of one doxycyclin aerosol particle following collision onto the peritoneal surface. The surface was previously covered with a thin layer of Escherichia coli (left picture at x1000 ML). (A) magnification of a raft in the central area of the doxocyclin layer (x20.000 ML). (B) Magnification of the outer border of the doxycyclin layer (x20.000 ML). ML, magnification levels. 

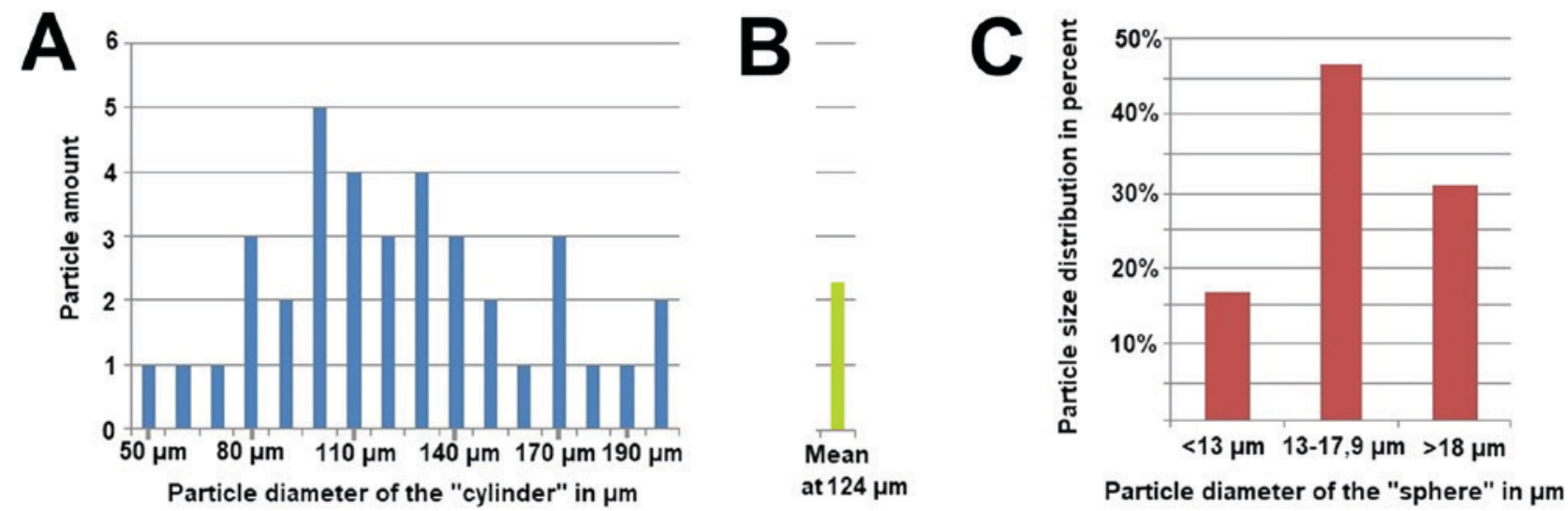

Figure 4. (A) Amount, distribution and diameter of cylindrical particles on peritoneal surface in an area of $4 \mathrm{~mm}^{2}$ are presented. (B) The mean particle amount for every measurement was calculated as well as a mean particle diameter for the cylindrical particles for that probe. (C) Calculated diameter of the initial spherical aerosol particles of the same sample before hitting the peritoneal surface. Diameters were grouped in $<13 \mu \mathrm{m}, 13-17.9 \mu \mathrm{m}$ and $>18 \mu \mathrm{m}$ and distribution of these groups were presented in percent to the total particle amount on the $4 \mathrm{~mm}^{2}$ sample.

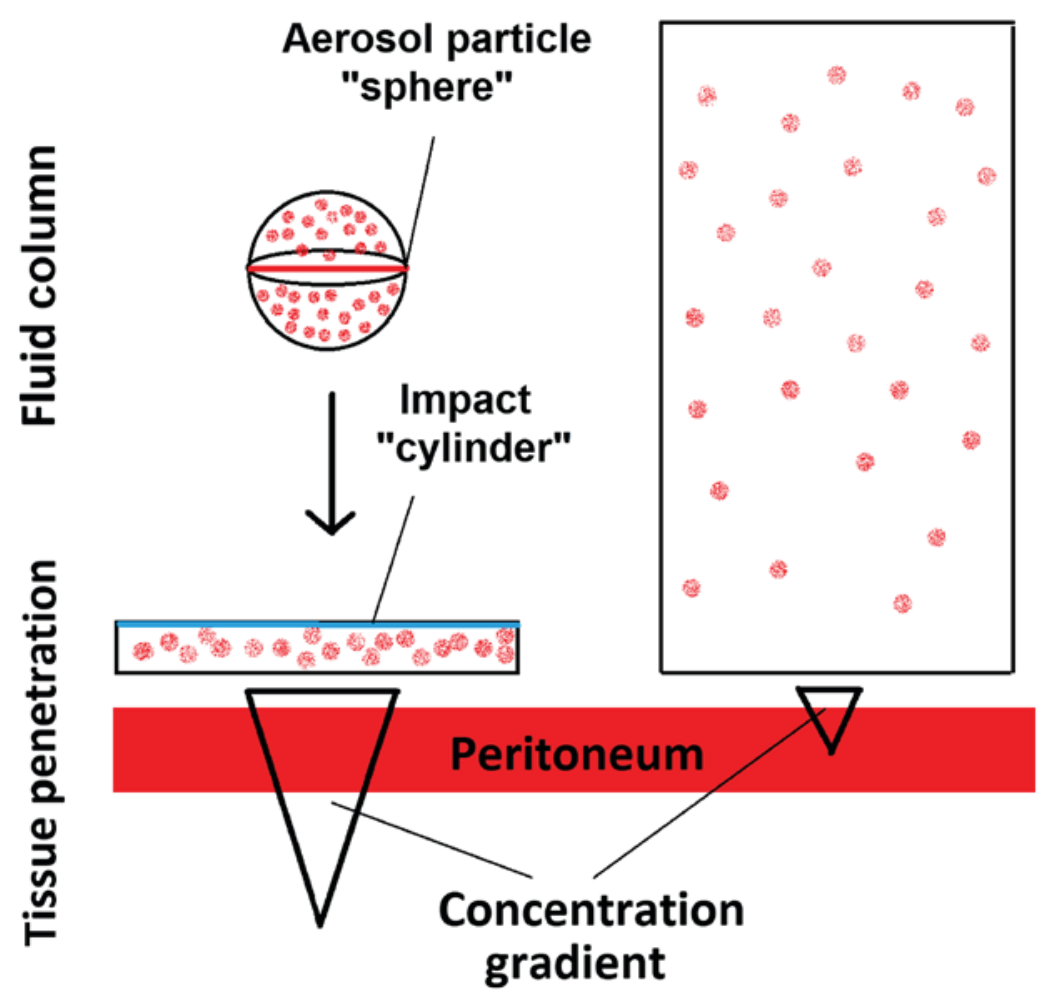

Figure 5. Proposed model of aerosol particle impaction and tissue penetration effect vs. lavage with the same total drug dose.

like' behavior and the idea of a therapeutic capnoperitoneum were not giving sufficient explanation to all observed effects and to the current experimental research. To this day, limited explanation was offered as to why a dispersion of a liquid with formation of aerosol particles claims improved distribution effects over liquid solutions. While initially the particles were assumed to range from 4 to $100 \mu \mathrm{m}$ in diameter (15), we are now aware that most of these particles are slightly larger than $5 \mu \mathrm{m}$ and show a peak at sizes of 13 to $18 \mu \mathrm{m}$. While the concentrations of chemotherapeutic solutions in PIPAC are in many cases higher than in liquid IPC installations, the total amount of the chemotherapeutic agent is much lower than in IPC. The demonstrated creation of a nanofilm by liquid droplets indicates that superior penetration rates in PIPAC are possibly due to the formation of a highly concentrated thin nanofilm which improves diffusion of chemotherapeutics into the peritoneal tissue. This could be caused by the concentration gradient and not by particle reabsorption or penetration. Fluid aerosol particles that carry more molecules inside than a corresponding liquid installation or lavage, disintegrate on contact with the peritoneum, and create a much wider fluid cylinder than the initial aerosol particle. A nanolayer is created by each impaction (Fig. 2A and B), resulting in a drug concentration increase over the peritoneal membrane according to Fick's basic law of diffusion to transperitoneal transport. The importance of this concept has been previously discussed (19). With this study, we are able to visualize the behavior of these aerosol particles on a submicroscopic level 
on the peritoneal surface for the first time, in the demonstrated manner.

We therefore propose the concept of the 'hyperconcentrated nanolayer' as an alternative based on this study and proven by many recent experimental studies (Fig. 5). Even at the same total drug amount, applied local drug concentrations in PIPAC are much higher than in liquid installations, as a higher diffusion gradient can be created by a thin drug layer. However, this model is restricted to non-complex, fluid aerosol particles.

Our results indicate that increasing the drug concentration of the aerosol particles by using a higher concentration of the applied medication could be a possible mechanism on how to improve antitumoral effects on the surface. Currently, clinical research on PIPAC is aiming to investigate as to whether dose increase may lead to an improved antitumoral effect (20). While pure fluid droplets seem to completely lose their spherical structure, liposomal particles and cells with some stable internal or external elements keep their shape. Until today, little data was available on how complex particles impact with the peritoneal surface and whether they can retain their shape following impaction. The application of more complex particles in PIPAC has only just begun (11). In the future, more studies will be conducted to investigate the role of complex particles in PIPAC application. The biological, technical and applicational aspects of these interactions need to be studied more intensively to draw further conclusions. With respect to the particular research interest on PIPAC, the introduction of this new view on the submicroscopic level of PIPAC and other aerosol therapies in the abdomen will be of particular interest in the future. While the critical point of this study is that we do not take the previously described drug distribution inhomogeneity of PIPAC into full account, this issue will be more illuminated in future studies $(15,16)$.

\section{Acknowledgements}

Not applicable.

\section{Funding}

This project was partially funded under the program of the Minister of Science and Higher Education of Poland "Strategy of Excellence - University of Research" in 2018-2019 project number 0019/SDU/2018/18.

\section{Availability of data and material}

The datasets used and/or analyzed during the present study are available from the corresponding author on reasonable request.

\section{Authors' contributions}

TK was responsible for study conception, project administration, investigation, manuscript writing and reviewing and editing the manuscript. VK undertook study conception, administration, investigation, writing the draft of the original manuscript. JS was responsible for the investigation, data analysis, manuscript writing and original draft preparation. HC undertook manuscript writing, the original draft preparation, data analysis and interpretation of data, drafting and critical revision for important intellectual content of the manuscript. JG performed the investigation and visualization experiments. MA and AM performed manuscript writing and reviewing, conception and design, drafting and critical revision for important intellectual content of the manuscript.

\section{Ethics approval and consent to participate}

The experiments were performed on peritoneal tissue samples from swine which are commercially available. Therefore, no approval of the Institutional Review Board and no consent of the Local Board on Animal Care were required.

\section{Patient consent for publication}

Not applicable.

\section{Competing interests}

The authors declare that they have no competing interests.

\section{References}

1. Solaß W, Hetzel A, Nadiradze G, Sagynaliev E and Reymond MA: Description of a novel approach for intraperitoneal drug delivery and the related device. Surg Endosc 26: 1849-1855, 2012.

2. Odendahl K, Solass W, Demtröder C, Giger-Pabst U, Zieren J, Tempfer C and Reymond MA: Quality of life of patients with end-stage peritoneal metastasis treated with Pressurized IntraPeritoneal Aerosol Chemotherapy (PIPAC). Eur J Surg Oncol 41: 1379-1385, 2015.

3. Khosrawipour T, Khosrawipour V and Giger-Pabst U: Pressurized Intra Peritoneal Aerosol Chemotherapy in patients suffering from peritoneal carcinomatosis of pancreatic adenocarcinoma. PLoS One 12: e0186709, 2017.

4. Khosrawipour V, Khosrawipour T, Diaz-Carballo D, Förster E, Zieren J and Giger-Pabst U: Exploring the spatial drug distribution pattern of pressurized intraperitoneal aerosol chemotherapy (PIPAC). Ann Surg Oncol 23: 1220-1224, 2016.

5. Khosrawipour V, Khosrawipour T, Falkenstein TA, Diaz-Carballo D, Förster E, Osma A, Adamietz IA, Zieren J and Fakhrian K: Evaluating the effect of micropump (C) position, internal pressure and doxorubicin dosage on efficacy of pressurized intra-peritoneal aerosol chemotherapy (PIPAC) in an ex vivo model. Anticancer Res 36: 4595-4600, 2016.

6. Khosrawipour V, Giger-Pabst U, Khosrawipour T, Pour YH, Diaz-Carballo D, Förster E, Böse-Ribeiro H, Adamietz IA, Zieren J and Fakhrian K: Effect of irradiation on tissue penetration depth of doxorubicin after pressurized intra-peritoneal aerosol chemotherapy (PIPAC) in a novel ex-vivo model. J Cancer 7: 910-914, 2016.

7. Khosrawipour V, Diaz-Carballo D, Acikelli AH, Khosrawipour T, Falkenstein TA, Wu D, Zieren J and Giger-Pabst U: Erratum to: Cytotoxic effect of different treatment parameters in pressurized intraperitoneal aerosol chemotherapy (PIPAC) on the in vitro proliferation of human colonic cancer cells. World J Surg Oncol 15: 94, 2017.

8. Khosrawipour V, Mikolajczyk A, Schubert J and Khosrawipour T: Pressurized intra-peritoneal aerosol chemotherapy (PIPAC) via endoscopical microcatheter system. Anticancer Res 38: 3447-3452, 2018

9. Khosrawipour V, Khosrawipour T, Hedayat-Pour Y, Diaz-Carballo D, Bellendorf A, Böse-Riberio H, Mücke R, Mohanaraja N, Adamietz IA and Fakhrian K: Effect of whole-abdominal irradiation on penetration depth of doxorubicin in normal tissue after Pressurized Intraperitoneal Aerosol Chemotherapy (PIPAC) in a post-mortem swine model. Anticancer Res 37: 1677-1680, 2017.

10. Khosrawipour V, Bellendorf A, Khosrawipour C, Hedayat-Pour Y, Diaz-Carballo D, Förster E, Mücke R, Kabakci B, Adamietz IA and Fakhrian K: Irradiation does not increase the penetration depth of doxorubicin in normal tissue after Pressurized Intra-peritoneal Aerosol Chemotherapy (PIPAC) in an ex vivo model. In Vivo 30: 593-597, 2016. 
11. Mikolajczyk A, Khosrawipour V, Schubert J, Chaudhry H, Pigazzi A and Khosrawipour T: Particle stability during Pressurized Intra-Peritoneal Aerosol Chemotherapy (PIPAC). Anticancer Res 38: 4645-4649, 2018.

12. DeCarlo PF, Slowik JG, Worsnop DR, Davidovits P and Jimenez JL: Particle morphology and density characterization by combined mobility and aerodynamic diameter Measurements. Part 1: Theory. Aerosol Sci Technol 38: 1185-1205, 2004.

13. Nowacki M, Grzanka D and Zegarski W: Pressurized intraperitoneal aerosol chemotheprapy after misdiagnosed gastric cancer: Case report and review of the literature. World J Gastroenterol 24: 2130-2136, 2018.

14. Nowacki $\mathrm{M}$ and Zegarski W: The scientific report from the first pressurized intraperitoneal aerosol chemotherapy (PIPAC) procedures performed in the eastern part of Central Europe. J Int Med Res 46: 3748-3758, 2018.

15. Göhler D, Khosrawipour V, Khosrawipour T, Diaz-Carballo D, Falkenstein TA, Zieren J, Stintz M and Giger-Pabst U: Technical description of the microinjection pump (MIP ${ }^{\circledR}$ ) and granulometric characterization of the aerosol applied for pressurized intraperitoneal aerosol chemotherapy (PIPAC). Surg Endosc 31: 1778-1784, 2017.

16. Khosrawipour T, Wu D, Bellendorf A, Mohanaraja N, Karabay E, Diaz-Carballo D and Khosrawipour V: Feasibility of single tumorspot treatment in peritoneal carcinomatosis via close range doxorubicin impaction in pressurized intra-peritoneal aerosol chemotherapy (PIPAC). J Clin Exp Oncol 6, 2017.
17. Kakchekeeva T, Demtröder C, Herath NI, Griffiths D, Torkington J, Solaß W, Dutreix M and Reymond MA: In vivo feasibility of electrostatic precipitation as an adjunct to pressurized intraperitoneal aerosol chemotherapy (ePIPAC). Ann Surg Oncol 23 (Suppl 5): S592-S598, 2016.

18. Göhler D, Große S, Bellendorf A, Falkenstein TA, Ouaissi M, Zieren J, Stintz M and Giger-Pabst U: Hyperthermic intracavitary nanoaerosol therapy (HINAT) as an improved approach for pressurised intraperitoneal aerosol chemotherapy (PIPAC): Technical description, experimental validation and first proof of concept. Beilstein J Nanotechnol 8: 2729-2740, 2017.

19. Elias DM and Sideris L: Pharmacokinetics of heated intraoperative intraperitoneal oxaliplatin after complete resection of peritoneal carcinomatosis. Surg Oncol Clin N Am 12: 755-769, xiv, 2003.

20. Tempfer CB, Giger-Pabst U, Seebacher V, Petersen M, Dogan A and Rezniczek GA: A phase I, single-arm, open-label, dose escalation study of intraperitoneal cisplatin and doxorubicin in patients with recurrent ovarian cancer and peritoneal carcinomatosis. Gynecol Oncol 150: 23-30, 2018.

This work is licensed under a Creative Commons Attribution-NonCommercial-NoDerivatives 4.0 International (CC BY-NC-ND 4.0) License. 